\title{
Diagnosis Performance of Cerebral Venous Thrombosis with Magnetic Resonance Imaging and Magnetic Resonance Venography in Zahedan (Southeast of Iran): A Series of 57 Patients
}

\author{
ShararehSaneiSistani ${ }^{1 \star}$, AliKhajeh ${ }^{2}$, HamedAmirifard ${ }^{3}$, MahdiMohammadi $^{4}$, HajarDerakhshandi ${ }^{1}$, BaharehHeshmatGhahderijani $^{1}$ \\ ${ }^{1}$ Department of Radiology, School of Medicine, Zahedan University of Medical Sciences, Zahedan, Iran; ${ }^{2}$ Department of \\ Pediatric Neurology, Children and Adolescents Health Research Center, Zahedan University of Medical Science, Zahedan, \\ Iran; ${ }^{3}$ Department of Neurology, School of Medicine, Zahedan University of Medical Sciences, Zahedan, Iran; ${ }^{4} \mathrm{Health}$ Promotion \\ Research Center, Zahedan University of Medical Sciences, Zahedan, IR Iran
}

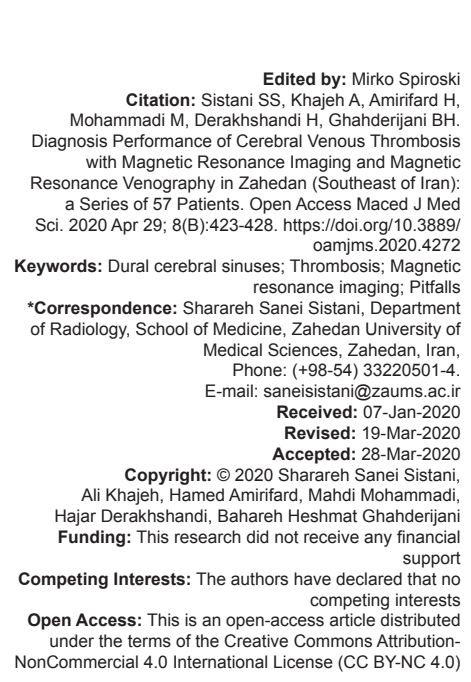

\section{Abstract}

BACKGROUND: Cerebral venous sinus thrombosis (CVST) is a scarce disease with poor prognosis and its diagnosis often challenges physicians due to nonspecific symptoms and widespread clinical manifestations.

AIM: To investigate the findings of magnetic resonance imaging (MRI) and magnetic resonance venography (MRV) of patients with CVST diagnosis in Ali Ebne Abitaleb Hospital in Zahedan during 2013-2016 and to evaluate imaging pitfalls involving in late diagnosis, complications, and even death.

METHODS: This retrospective descriptive study was done on 57 patients with confirmed CVST during 2013-2016 in Ali Ebne Abitaleb Hospital in Southeast of Iran (Zahedan). The MRI and MRV findings and related diagnostic pitfalls were evaluated. Twenty-one patients are pediatrics and 33 patients are adults.

RESULTS: Of 57 patients, evidences of cerebral edema were found in 33 patients, among whom 2 patients showed parenchymal edema (cerebral edema) without infarction, and 31 patients exhibited parenchymal edema with infarction. The frequency of involvement in descending order was as followed; transverse sinus (96.49\%), sigmoid sinus $(49.12 \%)$, superior sagittal sinus $(29.82 \%)$, jugular vein $(19.29 \%)$, internal cerebral veins $(7.01 \%)$, straight sinus $(5.2 \%)$, and cortical veins $(5.2 \%)$. Diagnostic pitfalls were also found in 8 patients. Seven patients exhibited acute and subacute thrombosis mimicked normal sinus flow void in T2-weighted images. No filling defect was seen on gadolinium-enhanced T1-weighted image in the other patient due to the sub-acute phase of thrombosis.

CONCLUSION: The delayed diagnosis of CVST originating from nonspecific clinical features and diagnostic imaging pitfalls can result in poor outcomes in patients. To prevent the diagnostic pitfalls, the clinician should give a brief history and clinical data and radiologist(s) should interpret the findings in addition to the use of advanced MR sequences.

\section{Introduction}

Cerebral venous sinus thrombosis (CVST) is considered as a rare life-threatening condition, which is associated with $0.5 \%$ of all stroke types, and affects 5 people per million each year [1], [2]. The disease can occur at any age, but the young age group constitutes the main patient population, and women account for $75 \%$ of adult patients [1], [3]. This increased risk in women seems to be related due to oral contraceptive use and prenatal and postpartum periods [2], [3], [4]. It is believed that the disease is underdiagnosed, thus early diagnosis requires a high clinical suspicion and the use of imaging modalities [3], [4].

CVST diagnosis often challenges physicians due to nonspecific symptoms and widespread clinical manifestations [5]. Early treatment greatly enhances the disease's prognosis, saves the lives of patients, improves their quality of life, and decreases family and social burden [6].

Overall, several factors such as severe dehydration, external injury, hematologic diseases, heart disease, pregnancy, infections, oral contraceptives, and immune disorders can be associated with CVST, whereas are not considered to be a susceptible cause in $20 \%$ of patients [7]. Imaging is of great importance in the diagnosis of CVST because of the nonspecific clinical picture and their variability [8].

The combination of magnetic resonance imaging (MRI) and magnetic resonance venography (MRV) is capable of increasing the sensitivity of CVST diagnosis to $90 \%$, and $\mathrm{MRI}$ in combination with MRV is the preferred method for diagnosis of CVST [9]. In MRI sequences, healthy dural sinuses are often seen in the form of no signal [10]. The main finding of CVST in the standard MRI protocol is the absence of a flow-void 
signal in standard T1 and T2 sequences [5]. The diagnosis of sinus thrombosis is based on the presence of a hyperintense signal on T1 and hyperintense or isointense signal on T2 and lack of flow signal (filling defect) in the MRV [2]. The presence of an abnormal T2 signal in a venous sinus can be the most reliable confirmatory diagnosis of thrombosis in comparison with the corresponding absence of flow, since blood flow is very slow, and it may have a high signal in T1 images, even in the absence of any thrombosis [4].

It is worth noting that chemical products of blood breakdown in thrombosis veins and sinuses have been defined to be associated alteration of T1- and T2-weighted images over time. Therefore, the actual manifestation and intensity of the intraluminal thrombus signal can change over time, which will be considerably dependent on the paramagnetic effects of products resulting from the breakdown of hemoglobin [5].

Changes in CVST signal in T1- and T2-weighted images may not be clear or even completely hidden, so their diagnosis requires a high clinical suspicion [5]. Investigating potential pitfalls in interpreting images are very essential for proper detection and prevention of false-negative results. The thrombosis signal may be very hypointense on T2-weighted images, and may mistakenly lead to a commentary on the absence of normal flow in sinus. Thus, the use of contrastenhanced MRV or computed tomography venography for diagnosis is needed at this stage [11].

This study aimed to investigate the findings of MRI and MRV in patients with CVST diagnosis in Ali Ibn Abi Talib Hospital in Zahedan during 2013-2016 and to evaluate imaging pitfalls involving in late diagnosis, complications, and even death.

\section{Methods}

Ethics approval was obtained from the institutional review board of Zahedan University of Medical Sciences, according to the Helsinki declaration. Written informed consent was signed by the parents of the pediatrics at study entry.

In this retrospective descriptive study, all patients who were treated with a diagnosis of CVST in Ali Ibn Abi Talib Hospital in Zahedan during 2013-2016 were enrolled. At the end of the study, 57 patients were diagnosed with CVST.

\section{Inclusion criteria included}

Patients diagnosed with CVST, who have their medical records, MRI, and MRV, were available at the hospital's PACS archive and also CVST was confirmed by the clinical findings and the imaging methods used.

\section{Exclusion criteria included}

Missing MRI and MRV in the PACS system of the hospital were excluded from the study.

\section{Data collection}

Findings of magnetic resonance imaging (MRI) and magnetic resonance venography (MRV) were assessed by the radiologist and their results were collected. Furthermore, to determine the diagnostic pitfalls in the imaging, a questionnaire containing all possible pitfalls was used.

Then, the frequency of various findings, including anatomical site involved (frontal, temporal, parietal, and occipital lobes, the thalamus, basal ganglia, internal capsule, cerebellum, and hippocampus), involved sinus (sinus caudal, transverse sinus, striate, sigmoid, deep vein of the brain, and jugular veins), hemorrhagic and non-hemorrhagic infarcts, intra-parenchymal hemorrhage, subacute hemorrhage, diffuse and localized cerebrospinal edema, midline shifts, evidence of infection (mastoiditis, abscess, and ethmoiditis meningitis), and brain herniation were determined in the images.

To evaluate possible diagnostic pitfalls, two radiologists were consulted that did not know the pathology of these patients. No other action was taken if each of these radiologists were able to easily diagnose CVST by examining the MRI and MRV of these patients. When MRI and MRV were reported to be a false negative, they were asked to complete a pre-made questionnaire. The questionnaire included a list of pitfalls that led to a false negative CVST diagnosis, which were extracted from similar studies. By assessing the data of these questionnaires, the most important reason for the lack of diagnosis of CVST in these patients was identified. Descriptive statistics, indexes, and tables were used for analyzing the data.

\section{Statistical analysis}

The data were analyzed using descriptive statistics and descriptive statistics. All statistical analysis was performed using statistical software (SAS version 9.1, SAS Institute Inc., Cary, North Carolina, USA).

\section{Results}

A total of 57 patients, who had been diagnosed with venous thrombosis, were enrolled in the study. Twenty-one patients belonged to the age group of infants and children and 36 patients were categorized into adult age group. 
Of the 21 patients in the pediatric group, 9 patients were under the age of 1 month, followed by a range of 1 month to 5 years ( 8 patients), 5-20 years (4 patients). The age range of the adult patients was determined, ranging from 20 to 78 years old, and the mean age was $39.23 \pm 13.47$. Of the 36 adult patients, 25 were female (69.44\%) and $11(30.55 \%)$ male.

\section{Distribution of cerebral vein structures in patients with CVST}

The involvement of cerebral vein sinus is presented in the table (Tables 1 and 2).

Table 1: Distribution of cerebral vein structures involvement in $\mathbf{5 7}$ patients understudy

\begin{tabular}{ll}
\hline Place of thrombosis & Number of patients (\%) \\
\hline Transverse sinus & $55(96.49)$ \\
Sigmoid sinus & $28(49.12)$ \\
Upper sagittal sinus & $17(29.82)$ \\
Cortical veins & $3(5.2)$ \\
Deep venous system & \\
$\quad$ Internal cerebral veins & $4(7.01)$ \\
Jugular vein & $11(19.29)$ \\
Straight sinus & $3(5.2)$ \\
\hline
\end{tabular}

\section{Brain parenchymal changes in the brain of patients with CVST}

Of 57 patients, 33 patients had evidence of edema in areas of the cerebral parenchyma, among which 2 patients showed parenchymal edema (cerebral edema) without infarction, and 31 patients exhibited parenchymal edema with infarction. Eight patients demonstrated cerebral edema in the focal region only in one lobe of the right or left hemisphere, and other patients in more than one lobe of a cerebral hemisphere or in parts of both cerebral hemispheres. Among 31 patients with venous infarction, 18 patients showed a hemorrhagic infarction and 13 non-hemorrhagic patients. In addition, hemorrhagic infarction was observed in two patients with subarachnoid hemorrhage $(\mathrm{SAH})$ and in one patient with subarachnoid and intravenous hemorrhage.

Table 2: Distribution of cerebral vein sinus involvement in $\mathbf{5 7}$ patients with diagnosis of CVST

\begin{tabular}{ll}
\hline Venous sinus involved & Number of patients \\
\hline Unilateral transverse sinus involvement & $13(22.80)$ \\
Bilateral transverse sinus involvement & $8(14.03)$ \\
Unilateral transverse and sigmoid sinus involvement & $9(15.78)$ \\
$\begin{array}{l}\text { Unilateral transverse and sigmoid sinus and jugular vein } \\
\text { involvement }\end{array}$ & $7(12.28)$ \\
$\begin{array}{l}\text { Unilateral transverse and sigmoid sinus and jugular vein } \\
\text { involvement + upper sagittal sinus }\end{array}$ & $1(01.75)$ \\
$\begin{array}{l}\text { Unilateral transverse and sigmoid sinus involvement and upper } \\
\text { sagittal sinus }\end{array}$ & $6(10.52)$ \\
$\begin{array}{l}\text { Bilateral transverse sinus involvement and upper sagittal sinus } \\
\text { Bilateral transverse sinus involvement+ unilateral sigmoid sinus } \\
\text { and jugular vein involvement + upper sagittal sinus }\end{array}$ & $1(01.75)$ \\
$\begin{array}{l}\text { Internal cerebrovascular involvement together with involvement of } \\
\text { other venous sinuses } \\
\text { straight sinus involvement together with involvement of other }\end{array}$ & $4(07.75)$ \\
$\begin{array}{l}\text { venous sinuses } \\
\text { Cortical veins involvement together with involvement of other } \\
\text { venous sinuses }\end{array}$ & $3(05.26)$ \\
$\begin{array}{l}\text { Bilateral transverse sinus involvement+ unilateral sigmoid sinus } \\
\text { and jugular vein involvement + upper sagittal sinus }\end{array}$ & $3(05.26)$ \\
\hline CVST: Cerebral venous sinus thrombosis. & $1(01.75)$ \\
\end{tabular}

\section{Diagnostic pitfalls}

Based on the results obtained from the examination of patients'MRI by two radiologists, diagnostic pitfalls were showed in 8 patients of 57 patients. Plus, in 7 patients, venous sinuses detected in the conventional MRI, but in all of these patients, CVST was detected by MRV images. In addition, with or without gadolinium injection, thrombosis was observed in all patients by MRV and only in 19 patients was seen by conventional MRI.

\section{Discussion}

Fordiagnosis ofpatientswithCVST, symptomatic patients and separate examination of sinuses in all brain MRI are of great importance [4], [10], [11]. The suspicious signs that require a closer look at the MRV are (1) failure of the signal void at the site of the venous sinuses (even vaguely and indeterminate), (2) observation of lateral and bilateral focal edema in the part of the brain with symmetrical or nonsymmetrical patterns, (3) observation of hemorrhagic or nonhemorrhagic infarction in part of brain parenchyma, (4) observation of hemorrhagic or non-hemorrhagic infarction in parts of the brain parenchyma that do not supply from an arterial trichotomy, (5) infarction or bleeding in brain parenchyma at infancy, childhood, and young age, especially in women of childbearing age and neonates, and (6) intravenous sinus dilation site with a non-diagnostic signal [4], [8], [11].

The lesions have been frequently demonstrated in many regions, including the cerebellum, basal nuclei, thalamus as a mass of gray matter, cerebral cortex, hippocampus, brain stem, subcortical white matter, external capsule, and splenium as previously described at MRI results in the literature [12], [13], [14].

Our findings revealed anatomical site involved including frontal, temporal, parietal, occipital lobe, thalamus, basal ganglia, internal capsule, cerebellum, and hippocampus), involved sinus (caudal, transverse sinus, striate, sigmoid, deep vein of the brain, and jugular veins).

Thrombosis of cerebral veins and sinuses along with elevation of venous and capillary pressures is considered as one of pathophysiological mechanisms for the development of cerebral venous thrombosis (CVT). Another mechanism is associated with a reduction of absorption of cerebrospinal fluid due to cerebral sinuses obstruction; both mechanisms are capable of promoting inductively coupled plasma, and vasogenic and cytotoxic edema, as well as hemorrhage [15], [16], [17].

Parenchymal abnormalities, including hemorrhagic and non-hemorrhagic infarcts, intraparenchymal hemorrhage, subacute hemorrhage, diffuse and localized cerebrospinal edema, midline shifts, evidence of infection (mastoiditis, abscess, 
ethmoiditis meningitis), and brain herniation) were determined based on imaging techniques.

Based on findings in the present study, hemorrhagic and non-hemorrhagic infarcts, intraparenchymal hemorrhage, subacute hemorrhage, diffuse and localized cerebrospinal edema, midline shifts, evidence of infection (mastoiditis, abscess, and ethmoiditis meningitis), and brain herniation. Edema is mainly frequent among 33 patients, including parenchymal edema with infarction (31 subjects) and parenchymal edema without infarction (2 subjects). Furthermore, 8 patients demonstrated cerebral edema in the focal region only in one lobe and/or more than one lobe, or in parts of both cerebral hemispheres.

Diffusion-weighted MR imaging is capable of providing a classification of parenchymal abnormalities in two categories, including primarily vasogenic edema and primarily cytotoxic edema. The presence of hemorrhage can be observed with both kinds of edema and different patterns [11], [18], [19].

Among 31 patients with venous infarction, hemorrhagic infarction was identified in 18 patients with CVT, of which SAH and subarachnoid along with intravenous hemorrhage were observed in 2 and 1 subjects, respectively, while 13 were non-hemorrhagic patients. It has been defined as intracerebral infarction, hemorrhage, and focal cerebral edema are among the most prevalent brain parenchymal lesions of CVT [20], [21].

Based on the findings in the literature, focal brain abnormalities and parenchymal lesions are more common in MR than CT findings [11], [22], [23], and also, focal edema without hemorrhage [18], [19], [24], [25].

Among the patients enrolled in this study, 8 patients revealed diagnostic pitfalls, among which 7 patients exhibited acute and subacute thrombosis mimicked normal sinus flow void in T2-weighted images, so they were neglected and not detected in the primary MRI.

These seven patients were young children and adults. Due to clinical symptoms, age, and clinical suspicion, MRV of patients showed thrombosis, except for one patient, where thrombosis was not observed in CE T1-weighted scan with contrast due to subclinical thrombosis; however, in mentioned patient, thrombosis was detected by combining data from contrast T1 and T2 sequences and sequences without contrast.

Empty delta sign has been found in sinus thrombosis at $\mathrm{CE}$ imaging. The presence of the empty delta sign has been previously found in $20 \%$ of subjects with sinus thrombosis by applying CECT. It can be also attributed a higher percentage when thin-section helical CT and volumetric MR images be used for diagnosis [11], [26]. On the other hand, normal findings of non-contrast head CT have been attributed to a percentage of $30 \%$ among patients with CVTs, with a high proportion of nonspecific abnormalities [27], [28], [29], [30], [31]. Of course, unenhanced MR imaging has been indicated to show high sensitivity for the diagnosis of venous thrombi, when compared with unenhanced CT [11].

A review study by Leach et al. showed that the superior sagittal sinus had the highest degree of involvement based on MRI images of 510 patients with CVST (61\%), followed by transverse sinus involvement $(57 \%)$, sigmoid sinus involvement $(15 \%)$, and straight sinus involvement (15\%). In addition, the frequency of other involvement areas is included in the following categories: Internal cerebral veins, jugular bulb, Galen vein, and cortical veins [11].

However, our findings demonstrated that the highest frequency of involvement was observed in the transverse sinus $(96.49 \%)$, sigmoid $(49.12 \%)$, superior sagittal sinus $(29.82 \%)$, and jugular veins $(19.29 \%)$, respectively, followed by internal cerebral veins ( $\% 7.01)$, cortical veins $(5.2 \%)$, and straight sinus (\% 2/5) were followed. These results are more or less in agreement with Leach et al., 2006 [11].

\section{Conclusion}

Taken together, to avoid delays in diagnosis, radiologists need to be aware of the various imaging characteristics of patients with CVT that can be likely hidden. To prevent the diagnostic pitfalls, the clinician should give a brief history and clinical data and radiologist(s) should interpret the findings in addition to the use of advanced MR sequences.

\section{Authors' Contributions}

Authors equally contributed to the manuscript.

\section{Ethical Publication Statement}

We confirm that we have read the Journal's position on issues involved in ethical publication and affirm that this report is consistent with those guidelines.

\section{References}

1. Capecchi M, Abbattista M, Martinelli I. Cerebral venous sinus thrombosis. J Throm Haemost. 2018;16(10):1918-31. https:// 
doi.org/10.1111/jth.14210

PMid:29923367

2. Souirti Z, Messouak $O$, Belahsen F. Cerebral venous thrombosis: A Moroccan retrospective study of 30 cases. Pan Afr Med J. 2014;17:281. https://doi.org/10.11604/pamj.2014.17.281.165 PMid:25317229

3. Khealani BA, Wasay M, Saadah M, Sultana E, Mustafa S, Khan FS, et al. Cerebral venous thrombosis: A descriptive multicenter study of patients in Pakistan and Middle East. Stroke. 2008;39(10):2707-11. https://doi.org/10.1161/ strokeaha.107.512814

PMid:18635853

4. Sajjad Z. MRI and MRV in cerebral venous thrombosis. J Pak Med Assoc. 2006;56(11):523-6.

\section{PMid: 17183982}

5. Selim M, Fink J, Linfante I, Kumar S, Schlaug G, Caplan LR Diagnosis of cerebral venous thrombosis with echo-planar T2*-weighted magnetic resonance imaging. Arch Neurol. 2002;59(6):1021-6. https://doi.org/10.1001/archneur.59.6.1021 PMid:12056941

6. Wang $X$, Sun X, Liu H. Clinical analysis and misdiagnosis of cerebral venous thrombosis. Exp Ther Med. 2012;4(5):923-7. PMid:23226750

7. Koopman K, Uyttenboogaart M, Hendriks HG, Luijckx GJ, Cramwinckel IR, Vroomen PC, et al. Thromboelastography in patients with cerebral venous thrombosis. Thromb Res. 2009;124(2):185-8. https://doi.org/10.3892/etm.2012.697 PMid:19187954

8. Zafar A, Ali Z. Pattern of magnetic resonance imaging and magnetic resonance venography changes in cerebral venous sinus thrombosis. J Ayub Med Coll Abbottabad. 2012;24(1):63-7. PMid:23855098

9. Qu H, Yang M. Early imaging characteristics of 62 cases of cerebral venous sinus thrombosis. Exp Ther Med. 2013;5(1):2336. https://doi.org/10.3892/etm.2012.796

PMid:23251274

10. Poon CS, Chang JK, Swarnkar A, Johnson MH, Wasenko J. Radiologic diagnosis of cerebral venous thrombosis: Pictorial review. AJR Am J Roentgenol. 2007;189 Suppl 6:S64-75. https://doi.org/10.2214/ajr.07.7015 PMid: 18029905

11. Leach JL, Fortuna RB, Jones BV, Gaskill-Shipley MF. Imaging of cerebral venous thrombosis: Current techniques, spectrum of findings, and diagnostic pitfalls. Radiographics. 2006;26 Suppl 1:S19-41. https://doi.org/10.1148/rg.26si055174 PMid: 17050515

12. Yilmaz TF, Aralasmak A, Toprak H, Guler S, Tuzun U, Alkan A. MRI and MR spectroscopy features of heat stroke: A case report. Iran J Radiol. 2018;15:34-9. https://doi.org/10.5812/ iranjradiol.62386

13. Li J, Zhang XY, Zou ZM, Wang B, Xia JK. Heat stroke: Typical MRI and 1H-MRS features. Clin Imaging. 2015;39(3):504-5. https://doi.org/10.1016/j.clinimag.2014.12.011 PMid:25586637

14. Mahajan S, Schucany WG. Symmetric bilateral caudate, hippocampal, cerebellar, and subcortical white matter MRI abnormalities in an adult patient with heat stroke. Proc (Bayl Univ Med Cent). 2008;21(4):433-6. https://doi.org/10.1080/089 98280.2008 .11928446

PMid: 18982090

15. Bousser MG, Ferro JM. Cerebral venous thrombosis: An update. Lancet Neurol. 2007;6(2):162-70. https://doi.org/10.1016/ s1474-4422(07)70029-7

PMid:17239803
16. Tanislav C, Siekmann R, Sieweke N. Cerebral vein thrombosis: Clinical manifestation and diagnosis. BMC Neurol. 2011;11:69. https://doi.org/10.1186/1471-2377-11-69 PMid:21663613

17. Stam J. Thrombosis of the cerebral veins and sinuses. N Engl J Med. 2005;352(17):1791-8. https://doi.org/10.1056/ nejmra042354

PMid:15858188

18. Yoshikawa T, Abe O, Tsuchiya K. Diffusion-weighted magnetic resonance imaging of Dural sinus thrombosis. Neuroradiology. 2002;44(6):481-8.

PMid:12070721

19. Lovblad KO, Bassetti C, Schneider J, Ozdoba C, Remonda L, Schroth G. Diffusion-weighted MRI suggests the coexistence of cytotoxic and vasogenic oedema in a case of deep cerebral venous thrombosis. Neuroradiology. 2000;42(10):728-73. https://doi.org/10.1007/s002340000395

PMid:11110073

20. Coutinho JM, Van den Berg R, Zuurbier SM, VanBavel E, Troost D, Majoie CB, et al. Small juxtacortical hemorrhages in cerebral venous thrombosis. Ann Neurol. 2014;75(6):908-16. https://doi.org/10.1002/ana.24180

PMid:24816819

21. Coutinho JM. Cerebral venous thrombosis. J Thromb Haemost. 2015;13 Suppl 1:S238-44. https://doi.org/10.1111/jth.12945 PMid:26149030

22. Yuh WT, Simonson TM, Wang AM, Koci TM, Tali ET, Fisher DJ, et al. Venous sinus occlusive disease: MR findings. AJNR Am J Neuroradiol. 1994;15(2):309-16.

PMid:8192079

23. Isensee C, Reul J, Thron D. Magnetic resonance imaging of thrombosed dural sinuses. Stroke. 1994;25(1):29-34. https:// doi.org/10.1161/01.str.25.1.29 PMid:8266378

24. DeVeber G, Andrew M, Adams C. Cerebral sinovenous thrombosis in children. N Engl J Med. 2001;345(6):417-23.

PMid:11496852

25. Bergui M, Bradac G. Clinical picture of patients with cerebral venous thrombosis and patterns of Dural sinus involvement. Cerebrovasc Dis. 2003;16(3):211-6. https://doi. org/10.1159/000071118

PMid: 12865607

26. Vogl TJ, Bergman C, Villringer A, Einhäupl K, Lissner J, Felix R. Dural sinus thrombosis: Value of venous MR angiography for diagnosis and follow-up. AJR Am J Roentgenol. 1994;162(5):1191-8. https://doi.org/10.2214/ ajr.162.5.8166009

PMid:8166009

27. Long B, Koyfman A, Runyon MS. Cerebral venous thrombosis: A challenging neurologic diagnosis. Emerg Med Clin North Am. 2017;35(4):869-78. https://doi.org/10.1016/j.emc.2017.07.004 PMid:28987433

28. Ferro JM, Canhao P, Stam J, Bousser MG, Barinagarrementeria F. Prognosis of cerebral vein and Dural sinus thrombosis: Results of the international study on cerebral vein and Dural sinus thrombosis (ISCVT). Stroke. 2004;35(3):664-70. https://doi. org/10.1161/01.str.0000117571.76197.26 PMid:14976332

29. Ferro JM, Canhao P, Stam J. Delay in the diagnosis of cerebral vein and Dural sinus thrombosis: Influence on outcome. Stroke. 2009;40(9):3133-8. https://doi.org/10.1161/ strokeaha.109.553891

PMid: 19608994

30. Piazza G. Cerebral venous thrombosis. Circulation. 
2012;125(13):1704-9.

PMid:22474313

31. Thorell SE, Parry-Jones AR, Punter M. Cerebral venous thrombosis-a primer for the haematologist. Blood Rev. 2015;29(1):45-50. https://doi.org/10.1016/j.blre.2014.09.006 PMid:25282690 